\title{
Cyclic carbonates based on vegetable oils
}

\author{
D. Miloslavskiy ${ }^{1}$, E. Gotlib ${ }^{1}$, O. Figovsky ${ }^{2, *}$, D. Pashin ${ }^{1}$ \\ ${ }^{1}$ Kazan National Research Technical University named after A.N. Tupolev, \\ 10, K.Marx St., Kazan, Tatarstan 420111, Russian Federation \\ ${ }^{2}$ INRC Polymate, Migdal Ha'Emeq, Israel \\ *E-mail address: figovsky@netvision.net.il
}

\begin{abstract}
The analysis of literary data on the obtaining of cyclic carbonates based on the vegetable oils has been carried out. The influence on carbonation reaction the type of vegetable oil, the chemical composition and catalyst concentration, state of carbon dioxide, pressure and temperature have thus been considered. The carbonation process of epoxidized oils that are valuable renewable vegetable raw materials is studied insufficiently.
\end{abstract}

Keywords: epoxidized vegetable oil; carbonation; carbon dioxide; non-isocyanate polyurethane

\section{INTRODUCTION}

Various ways of the five-membered cyclic carbonates (CC) usage have been described in literature, some of them are given in the review [1]. Special attention is paid to the receiving of different polymers on $\mathrm{CC}$ basis $[1,2]$, among which the so-called non-isocyanate polyurethanes (NIPU) are of the greatest interest [3].

Against the background of the world ecological legislative pressure, there arises the necessity of transition to "green technologies", namely to the use of non-toxic renewable raw materials, for example, on the basis of vegetable products. Another factor that impels to search raw materials alternative to mineral sources is that according to the most pessimistic forecasts, the explored reserves of petroleum will be enough for the humanity only till 2056 [4] at the modern rates of consumption.

The recent decades are characterized by researches aimed to apply carbon dioxide (CD) in large-capacity chemistry. In many respects it is defined by the growth of CD emissions in the atmosphere that is considered as the main reason for "global warming". So, CD consumption in the already existing processes is at the level of 110 million tons, it does not exceed even $1 \%$ of its annual atmosphere pollution [4].

In this regard, it was interesting to generalize the literary data devoted to the synthesis of cyclic carbonates on the basis of vegetable oils, subjected to epoxidation, and the main greenhouse gas - carbon dioxide. 


\section{MAIN PART}

Works on the synthesis of cyclic carbonate vegetable oils (CCVO) can be conditionally classed into 3 groups according to the technological processing. The first group contains the processes carried out at the atmospheric pressure by barbotage epoxide-content oils by carbon dioxide. The processes which are carried out at the increased pressure in autoclaves make the second group. The third group includes processes in the supercritical carbon dioxide (ScCD) environment. It should be noted that in some works the CCVO synthesis was considered as the stage to receive raw materials for NIPU and, thus, a little attention was paid to the study of carbonation process [5].

The main part of researches is devoted to epoxidized soybean oil (ESBO) carbonation [6-12], in some works the epoxidized linseed oil (ELSO) $[5,13]$ is used. Such choice is defined by the availability of these oils which are large-capacity products [14], they are widely applied at halogenated polymers processing (for example, polyvinylchloride).

Besides, an important factor is their high functionality (not less than 4 epoxy groups (EG) in a triglyceride molecule for ESBO, and from 5 (EG) - for ELSO) that defines the crosslink density of potential NIPU. The choice of unsaturated vernonia oil as raw materials [12] seems to be interesting despite its smaller functionality $(\sim 3)$, it allows to receive the product of carbonation with a considerably low viscosity. It is important as during carbonation the viscosity of epoxidized vegetable oil (EVO) grows by tens times.

There are also data about carbonation of epoxidized cotton seed oil (ECSO) in laboratory conditions (functionality is $\sim 3$ ), for the purpose of its trial as a component of lubrications [15]. Despite the wide range of catalysts, applied to obtain CC [1,2,4], catalytic systems on the basis of tetrabutylammonium bromide (TBAB) have become widely applied for CCVO synthesis [5-7,9-13,15], they are a large-capacity industrial product. The optimum of TBAB dosage is $2 \div 7 \mathrm{~mol} \%$, as relating to epoxy groups of a substrate. Besides individual TBAB, two-component systems with its application are also described: $\left\{\mathrm{TTBAB}+\mathrm{SnCl}_{4}\right\}$ [10] and $\left\{\mathrm{TBAB}+\mathrm{H}_{2} \mathrm{O}\right\}$ [9]. At the same time such catalytic systems as: sodium iodide, lithium bromide and potassium, benzyltrimethylammonium bromide, ion exchange resins Amberlite IRA-400 (Cl) are [6] of little effect [11], due to their low or full insolubility in the substratum.

Successful application of potassium iodide to receive CCVO is possible only in case of its activation by 18-krown-6 ether [8]. Heterogeneous catalytic system (silica-supported 4pyrrolidinopyridinium iodide on $\mathrm{SiO}_{2}\left(\mathrm{SiO}_{2}-\mathrm{I}\right)$ [13] which has well proved in the process of propylene oxides and styrole carbonation [16], has appeared not so successful for CCVO synthesis. The generalized data on researches of epoxidized vegetable oils carbonation process presented in Table 1.

Table 1. The generalized data on researches of epoxidized vegetable oils carbonation process.

\begin{tabular}{|c|c|c|c|}
\hline Oil & Catalyst system & Variant of synthesis & Reference \\
\hline ESBO & TBAB & Atmosphere pressure & 6 \\
\hline ESBO & TBAB & $\begin{array}{c}\text { Atmosphere pressure } \\
\text { Increased pressure }\end{array}$ & 7 \\
\hline ESBO & $\mathrm{KI}+18$-crown-6 ether & Increased pressure & 8 \\
\hline ELSO & $\mathrm{TBAB}, \mathrm{SiO}_{2}-\mathrm{I}$ & Atmosphere pressure & 13 \\
\hline
\end{tabular}




\begin{tabular}{|c|c|c|c|}
\hline & & Increased pressure & \\
\hline ELSO & TBAB & Atmosphere pressure & 5 \\
\hline ESBO & $\mathrm{TBAB}+\mathrm{H}_{2} \mathrm{O}$ & Atmosphere pressure & 9 \\
\hline ESBO & $\mathrm{TBAB}+\mathrm{SnCl}_{4}$ & Increased pressure & 10 \\
\hline ESBO & $\mathrm{TBAB}$ & In ScCD environment & 11 \\
\hline ESBO, vernonia oil & $\mathrm{TBAB}$ & In ScCD environment & 12 \\
\hline ECSO & $\mathrm{TBAB}$ & Increased pressure & 15 \\
\hline
\end{tabular}

\section{1. Atmospheric pressure synthesis}

The low volatility of vegetable oils and their derivatives allows to conduct synthesis with their participation at the atmospheric pressure and temperatures close to $200{ }^{\circ} \mathrm{C}$ [17]. The first work on the receiving of CCVO was carried out at the atmospheric pressure [6] in 2004. In the following years the carbonation of epoxidized oils at the atmospheric pressure was carried out by a number of researchers $[5-9,13]$, who noted a considerable period of time (as a rule, some days) necessary for the achievement of high values of EG oil conversion, and the fast growth of viscosity in the process of carbonation.

Javni, comparing the results of ESBO carbonation, obtained by his group, and the data presented by Tamami [6] (synthesis was carried out in the identical conditions: ESBO with the epoxy oxygen of $6.8 \mathrm{wt} . \%$, atmospheric pressure, $110{ }^{\circ} \mathrm{C}$ ), assumed that Tamami's results on the achievement of conversion of $94 \%$ are wrong. The comparison of EG conversion data received by infrared spectroscopy method and a titrimetric method (100 and $78 \%$ respectively) made the basis of such assumption and showed that the chemical method gives more precise results [7]. The data of physical-mechanical NIPU testing testify indirectly to a lower than $94 \%$ conversion of EG for CC obtained by Tamami [7].

Javni and Tamami did not note the formation of oligomeric products, the results of gelpermeation chromatography (GPC) $[6,7]$ testified to this. There are no data on the optimum of CCVO synthesis temperature at atmospheric pressure. Javni compared the processes at 110 and $140{ }^{\circ} \mathrm{C}$ and did not come to the singlevalued conclusion. He assumed the behavior of TBAB decomposition reaction at $140{ }^{\circ} \mathrm{C}$. However, later Doll instrumentally proved that this process is observed only at temperatures over $150{ }^{\circ} \mathrm{C}[11]$.

At the carbonation at the atmospheric pressure [13], carrying out the synthesis at 140 ${ }^{\circ} \mathrm{C}$ : the EG conversion equal to $85 \%$ was achieved within 89 hours.

Perhaps, the most interesting results were obtained by Mazo and his group [9]. To intensify the carbonation process there was added some water in the reaction mixture in the quantity determined by the ratio $[\mathrm{H} 2 \mathrm{O}]:[\mathrm{EG}]=1: 3$, mol., the choice of which is explained by the results of the work carried out earlier [18]. The addition of water allowed to increase the rate of carbonation up to $30 \%$ approximately. On the whole, it is possible to make the conclusion that the full conversion of EG oil in the carbonation process at the atmospheric pressure is practically unattainable, though receiving of CCVO with the functionality over 2 suitable for synthesis of linear polymers is possible.

The synthesis of CCVO in itself in such a way is simple and does not demand special equipment, but because of the process time it is of low attractiveness for practical 
implementation. The generalized data on processes of EVO carbonation at the atmospheric pressure presented in Table 2.

Table 2. The generalized data on processes of EVO carbonation at the atmospheric pressure.

\begin{tabular}{|c|c|c|c|c|c|c|}
\hline \multirow[b]{2}{*}{ Oil $\left(\mathrm{OC}^{*}\right)$} & \multirow[b]{2}{*}{$\begin{array}{c}\text { Kat } \\
\text { (Concentration } \\
\text { mol.\%,) }\end{array}$} & \multirow[b]{2}{*}{$\mathrm{T},{ }^{\circ} \mathrm{C}$} & \multicolumn{3}{|c|}{ Result } & \multirow[b]{2}{*}{ Reference } \\
\hline & & & Time, $\mathrm{h}$ & $\begin{array}{c}\text { EG } \\
\text { conversion, } \\
\%\end{array}$ & $\begin{array}{l}\text { Characteristic of } \\
\text { product }\end{array}$ & \\
\hline $\begin{array}{c}\text { ELSO } \\
(8.5 \div 10)\end{array}$ & TBAB (5) & 110 & 72 & $\mathrm{n} / \mathrm{a}$ & $\begin{array}{c}\text { Viscos. }-13.2 \mathrm{Pas} \\
\left(25^{\circ} \mathrm{C}\right) \\
\mathrm{M}_{\mathrm{w}}-2600\end{array}$ & 5 \\
\hline ESBO (6.8) & TBAB (5) & 110 & 72 & $94 * *$ & $\begin{array}{c}\text { Viscos. }-13.2 \mathrm{~Pa} \text { s } \\
\left(25^{\circ} \mathrm{C}\right)\end{array}$ & 6 \\
\hline \multirow{3}{*}{ ESBO (6.8) } & \multirow{3}{*}{ TBAB (2.5) } & \multirow{2}{*}{110} & 50 & 63 & $\begin{array}{c}\text { Viscos. }-13.2 \mathrm{~Pa} s \\
\left(25^{\circ} \mathrm{C}\right)\end{array}$ & \multirow{3}{*}{7} \\
\hline & & & 89 & 78 & \multirow{2}{*}{$\mathrm{n} / \mathrm{a}$} & \\
\hline & & 140 & 100 & 62 & & \\
\hline \multirow{5}{*}{ ESBO (6.2) } & \multirow{2}{*}{ TBAB (5) } & \multirow{5}{*}{120} & 29 & 50 & \multirow{4}{*}{$\mathrm{n} / \mathrm{a}$} & \multirow{5}{*}{9} \\
\hline & & & 70 & 80 & & \\
\hline & \multirow{3}{*}{$\begin{array}{c}\operatorname{TBAB}(5)+\mathrm{H}_{2} \mathrm{O} \\
{[\mathrm{EG}]:\left[\mathrm{H}_{2} \mathrm{O}\right]=} \\
3: 1\end{array}$} & & 20 & 50 & & \\
\hline & & & 47 & 80 & & \\
\hline & & & 70 & 90 & Selectivity $-90 \%$ & \\
\hline \multirow[b]{2}{*}{ ELSO (8.9) } & TBAB (2) & \multirow[b]{2}{*}{140} & 96 & 91 & \multirow[b]{2}{*}{$\mathrm{n} / \mathrm{a}$} & \multirow[b]{2}{*}{13} \\
\hline & $\begin{array}{l}\mathrm{SiO}_{2}-\mathrm{I}[\mathrm{EG}]:[\mathrm{I}] \\
\quad=1: 0.03\end{array}$ & & 170 & 53 & & \\
\hline
\end{tabular}

*Oxirane content, wt.\%

** According to Javni's [7] data, the viscosity of a product with the $94 \%$ conversion of EG obtained by Tamami within three days [6], corresponds to the product received by his group during 50 hours, the EG conversion of which made $63 \%$.

\section{2. Synthesis at the increased pressure}

From the point of view of time spent on the reaction, the performing of the process at the increased pressure seems more perspective, that is shown by a number of authors $[7,10$, 13, 15]. The first data about the influence of pressure upon EVO carbonation were submitted by Javni [7]. So, for example, the increase of pressure from 1 to $0.34 \mathrm{MPa}$ allows to reduce the time of product synthesis with EG conversion up to $\sim 80 \%$ from 90 to 40 hours. Considered by Javni pressure maximum $(5.65 \mathrm{MPa})$ at the synthesis temperature of $140{ }^{\circ} \mathrm{C}$ allowed to receive CCVO with EG complete conversion within a day. However, researchers have no consensus about the optimum pressure at CCVO synthesis. So, for example, $L i$ gives data that pressure growth higher than 1.5 MPa does not give a positive result [10].

On the whole, products with EG high conversion ( $>90 \%$ ) are obtained during 10-23 hours at the increased pressure $[7,10,13,15]$. Processes, both at the atmospheric and increased 
pressure, are characterized by considerable rate drop of carbonation with the growth of EG conversion of oil. For example, the achievement of EG conversion up to $87 \%$ during 10 hours of the reaction, during 20 hours $-95.5 \%$, and 30 hours $-98 \%$ is shown in Li's work [10]. These data are especially interesting if to consider CCVO as raw materials for the synthesis of NIPU. So, when the influence of cyclic carbonate groups (CCG) content of soybean oil on NIPU properties has been investigated, it has been revealed that the optimum characteristics are achieved at the quantity of $3 \mathrm{EG}$ on a triglyceride molecule (EG conversion - 74-85\%) [10]. Due to this, the time of CCVO synthesis can be reduced considerably, and the problem of their high viscosity can be solved as well. The data obtained by Bähr and colleagues [13] are of considerable interest. The authors achieved the complete EG conversion of linseed oil at the pressure of $3 \mathrm{MPa}$ during less than 10 hours [13], though the dosage of TBAB was the minimum of all considered works ( 2 mol. \%) (Table 3$)$. It is the most probable that the reason of it depends on side reactions, as GPC data molecular mass (MM) of the product is $\sim 2000$, that approximately exceeds theoretical value by 1.4 times) and also the content of CCG (26.7 wt. \%, that is nearly by 1.5 times lower than theoretical values) evidence. These data are especially interesting if to consider them from the point of view of the choice of substratum for carbonation. Based on Bähr, Mahendran and colleagues [5] were engaged in ELSO carbonation as well, their results also testify to side reactions (MM of the product almost twice exceeds the theoretical value) (Table 2). The generalized data on processes of EVO carbonation at the increased pressure presented in Table 3.

Table 3. The generalized data on processes of EVO carbonation at the increased pressure.

\begin{tabular}{|c|c|c|c|c|c|c|c|}
\hline \multirow{3}{*}{$\begin{array}{l}\text { Oil } \\
\text { (OC) }\end{array}$} & \multirow{3}{*}{$\begin{array}{c}\text { Kat } \\
\text { (Concentration mol. \%) }\end{array}$} & \multirow{2}{*}{\multicolumn{2}{|c|}{$\begin{array}{l}\text { Conditions of } \\
\text { carrying out } \\
\text { synthesis }\end{array}$}} & \multicolumn{3}{|c|}{ Result } & \multirow{3}{*}{ Reference } \\
\hline & & & & \multirow{2}{*}{$\begin{array}{c}\text { Time, } \\
\mathrm{h}\end{array}$} & \multirow{2}{*}{$\begin{array}{c}\text { EG } \\
\text { conversion, } \\
\%\end{array}$} & \multirow{2}{*}{ Characteristic of product } & \\
\hline & & $\begin{array}{l}\mathrm{T}, \\
{ }^{\circ} \mathrm{C}\end{array}$ & $\begin{array}{c}\text { Pressure, } \\
\mathrm{MPa}\end{array}$ & & & & \\
\hline \multirow{6}{*}{$\begin{array}{c}\text { ESBO } \\
(6.8)\end{array}$} & \multirow{6}{*}{ TBAB (2.5) } & 140 & \multirow{3}{*}{1.03} & \multirow{3}{*}{23} & 96 & Viscos. $-32.0 \mathrm{Pas}\left(25^{\circ} \mathrm{C}\right)$ & \multirow{6}{*}{7} \\
\hline & & 160 & & & 90 & \multirow{4}{*}{$\mathrm{n} / \mathrm{a}$} & \\
\hline & & 180 & & & 40 & & \\
\hline & & 160 & \multirow{2}{*}{0.69} & \multirow{2}{*}{23} & 91.8 & & \\
\hline & & 180 & & & 44.1 & & \\
\hline & & 140 & 5.65 & 22 & 97.8 & Viscos.- 33.0 Pas $\left(25^{\circ} \mathrm{C}\right)$ & \\
\hline \multirow{3}{*}{$\begin{array}{l}\text { ESBO } \\
(6.4)\end{array}$} & \multirow{3}{*}{$\begin{array}{l}\mathrm{KI}+18 \text {-crown- } 6 \text { ether } \\
(0.3 \text { mass. } / 0.2 \text { mass. })\end{array}$} & \multirow{3}{*}{130} & \multirow{3}{*}{6.0} & 12 & 20.5 & Viscos.- $0.87 \mathrm{~Pa} \cdot\left(20^{\circ} \mathrm{C}\right)$ & \multirow{3}{*}{8} \\
\hline & & & & 48 & 68.7 & Viscos. $-12.4 \mathrm{~Pa}$ s $\left(20^{\circ} \mathrm{C}\right)$ & \\
\hline & & & & 120 & 98.3 & Viscos. $-30.0 \mathrm{~Pa}$ s $\left(20^{\circ} \mathrm{C}\right)$ & \\
\hline \multirow{6}{*}{$\begin{array}{c}\text { ESBO } \\
(6.8)\end{array}$} & $\mathrm{SnCl}_{4} \cdot 5 \mathrm{H}_{2} \mathrm{O}(3)$ & \multirow{3}{*}{120} & \multirow{3}{*}{1.0} & \multirow{3}{*}{20} & 64.4 & \multirow{3}{*}{$\mathrm{n} / \mathrm{a}$} & \multirow{6}{*}{10} \\
\hline & TBAB (3) & & & & 71.3 & & \\
\hline & $\begin{array}{c}{[\mathrm{TBAB}]:\left[\mathrm{SnCl}_{4}\right]=1: 3} \\
(3)\end{array}$ & & & & 89.2 & & \\
\hline & \multirow{3}{*}{$\begin{array}{c}{[\mathrm{TBAB}]:\left[\mathrm{SnCl}_{4}\right]=1: 3} \\
(3)\end{array}$} & \multirow{3}{*}{140} & \multirow{3}{*}{1.5} & 10 & 86.9 & Viscos.- 11.3 Pas $\left(25^{\circ} \mathrm{C}\right)$ & \\
\hline & & & & 20 & 95.5 & Viscos. $-16.4 \mathrm{~Pa}$ s $\left(25^{\circ} \mathrm{C}\right)$ & \\
\hline & & & & 30 & 98.5 & Viscos.- 19.3 Pas $\left(25^{\circ} \mathrm{C}\right)$ & \\
\hline \multirow{3}{*}{$\begin{array}{l}\text { ELSO } \\
(8.9)\end{array}$} & \multirow{2}{*}{ TBAB (2) } & \multirow{3}{*}{140} & 1.0 & $\sim 20$ & complete & \multirow{3}{*}{ CCG content 26.7 wt. $\%$} & \\
\hline & & & 3.0 & $<10$ & complete & & 13 \\
\hline & $\begin{array}{c}\mathrm{SiO}_{2}-\mathrm{I} \\
{[\mathrm{EG}]:[\mathrm{I}]=1: 0.03}\end{array}$ & & 3.0 & 45 & complete & & \\
\hline ECSO & TBAB (3.75) & 140 & 3.0 & 24 & 99,9 & $\mathrm{n} / \mathrm{a}$ & 15 \\
\hline
\end{tabular}




\section{3. Synthesis in the environment of supercritical carbon dioxide}

The particular case of synthesis at the increased pressure is the conducting of the process in the ScCD environment, i.e. under such condition of carbon dioxide when the difference between its liquid and gas phase disappears. CD transition to the supercritical condition is observed at the temperature and pressure above critical, equal to $31.1^{\circ} \mathrm{C}$ and 7.38 MPa respectively [12]. ScCD is not toxic, it is not combustible, it can be transferred to green solvents. ScCD can be "adjusted", i.e. varying the temperature and pressure it is possible to change its density, polarity, solubility parameter, thus reaching the optimum of properties necessary for the specific reaction [12].

In the field of CCVO synthesis the carrying out of the reaction in $\mathrm{ScCD}$ environment has found its reflection only in two works [11,12], differing mostly by the use of various substrata (ESBO and vernonia oil). At the transition from carbonation process at the atmospheric pressure to the process in $\mathrm{ScCD}$ environment, the considerable reduction of time for the obtaining of equal EG conversion is observed. Nevertheless, the application of CD does not give time advantage in comparison with processes at the increased pressure $[7,10,13,15]$, and its use complicates and increases the price of technology. However, in the works on the carbonation in $\mathrm{CD}$ environment the optimization of conditions has not been performed, that probably defines low results. Thus, the synthesis was carried out at the temperature of $100{ }^{\circ} \mathrm{C}$, while the best results were obtained at the temperature of $140{ }^{\circ} \mathrm{C}$ $[7,10,13,15]$. The generalized data of EVO carbonation processes in ScCD environment presented in Table 4.

Table 4. The generalized data of EVO carbonation processes in ScCD environment.

\begin{tabular}{|c|c|c|c|c|c|c|c|}
\hline \multirow{3}{*}{$\begin{array}{l}\text { Oil } \\
\text { (OC) }\end{array}$} & \multirow{3}{*}{$\begin{array}{c}\text { Kat } \\
\text { (Concentration } \\
\text { mol. \%) }\end{array}$} & \multirow{2}{*}{\multicolumn{2}{|c|}{$\begin{array}{l}\text { Conditions of } \\
\text { carrying out } \\
\text { synthesis }\end{array}$}} & \multicolumn{3}{|c|}{ Result } & \multirow{3}{*}{ Reference } \\
\hline & & & & \multirow{2}{*}{ Time, $\mathrm{h}$} & \multirow{2}{*}{$\begin{array}{c}\text { EG } \\
\text { conversion, } \\
\%\end{array}$} & \multirow{2}{*}{ Characteristic of product } & \\
\hline & & $\begin{array}{l}\mathrm{T}, \\
{ }^{\circ} \mathrm{C}\end{array}$ & $\begin{array}{l}\text { Pressure, } \\
\mathrm{MPa}\end{array}$ & & & & \\
\hline \multirow{3}{*}{$\begin{array}{c}\text { ESBO } \\
(7.0)\end{array}$} & \multirow{3}{*}{ TBAB (5) } & \multirow{3}{*}{100} & \multirow{3}{*}{10.3} & 10 & 82 & Viscos. $-70 \mathrm{~Pa} \cdot \mathrm{s}\left(25^{\circ} \mathrm{C}\right)$ & \multirow{3}{*}{11} \\
\hline & & & & 20 & 94 & Viscos.- $145 \mathrm{~Pa}$ s $\left(25^{\circ} \mathrm{C}\right)$ & \\
\hline & & & & 40 & 100 & Viscos.- $170 \mathrm{Pas}\left(25^{\circ} \mathrm{C}\right)$ & \\
\hline $\begin{array}{c}\text { ESBO } \\
(6.9)\end{array}$ & \multirow[t]{2}{*}{ TBAB (7) } & \multirow[t]{2}{*}{100} & \multirow[t]{2}{*}{13.8} & \multirow[t]{2}{*}{46} & 90.1 & $\begin{array}{c}\text { Viscos. }-7.0 \text { Pas }\left(25^{\circ} \mathrm{C}\right) \\
\text { Degree of carbonation }> \\
72 \% \\
\end{array}$ & \multirow[t]{2}{*}{12} \\
\hline $\begin{array}{l}\text { Vernonia } \\
\text { oil (4.1) }\end{array}$ & & & & & 87.5 & $\begin{array}{l}\text { Viscos. }-0.99 \mathrm{Pas}\left(25^{\circ} \mathrm{C}\right) \\
\text { Degree of carbonation } 72 \%\end{array}$ & \\
\hline
\end{tabular}

GPC data give evidence of CC with MM formation close to theoretical, and also of a slight share of oligomeric products (about $2.5 \%$ ). Meanwhile, viscosity values of products carbonation given by Doll require some attention (Table 4). They exceed the corresponding indexes of products with similar EG conversion given by other researchers by times [6-8]. At the same time the viscosity of the initial ESBO is commensurable with the data of other works that does not allow to explain such difference by a simple error of measurements. 
Besides, at a long time of synthesis, higher concentration of TBAB, use of a specially made stirrer and higher pressure in the reactor, Mann obtained the product with EG conversion of $90 \%$ level [12], i.e. with the properties corresponding to CCECSO that Doll obtained during 20 hours (EG conversion is $94 \%$ ). Probably, this is because of the change of ScCD solubility parameter due to the increased pressure.

The way the components are mixed up makes its contribution. The data of Tamami's [6] and Javni's [7] works serve as an illustration of it. There the carbonation of soybean oil with the equal content of epoxy oxygen $(6.8 \mathrm{wt} . \%)$ was carried out in the similar conditions (atmospheric pressure, temperature is $110^{\circ} \mathrm{C}$, loading of ESBO - 200 grams). Thereat, Javni having cut the dosage of TBAB by half (to $2.5 \mathrm{~mol}$. \% reached EG conversion of $63 \%$ for 20 hours faster than Tamami [6].

The most probable explanation for this can be the use by the latter of a magnetic stirrer for agitating, ineffective for the considered volume of a substrate. Mazo and colleagues registered the acceleration of carbonation reaction in the process of agitating intensity increase, up to the stirrer rotation frequency of $400 \mathrm{rpm}$ [9].

Researchers have no consensus concerning the optimum content of tetrabutylammonium bromide. The concentration from 2 [13] to 7 mol. \% [12] is given, as to EG. According to [7], the concentration of TBAB $2.5 \mathrm{~mol} \%$ is sufficient in order to obtain high values of EG conversion, and the increase of catalyst dosing leads to the growth of the reaction rate. The data presented by Mazo and colleagues [9] demonstrate the same.

The issue of carbonation process acceleration reasonability by means of catalyst concentration increase is closely related to the economy and, respectively, to the possibility of its disengagement from the reaction mass for the subsequent use. The subject of the desired product cleaning from catalyst is also important.

\section{4. Removing of catalytic system from the product}

If the heterogeneous catalytic system can be removed by means of simple filtering and after washing out is reused, the homogeneous one, such as TBAB, has a more complicated process. At the same time, TBAB has such an advantage as different ways of its removal out of the reaction mass, some part of which can be reused.

The first variant was described in Tamami's [6] work: removing of catalyst out of reaction mass was carried out by means of its dissolving in ethyl acetate and the subsequent extraction of TBAB by warm water. At the following stage the solvent was driven away. This method has found its application in several works $[7,10,11,15]$.

The alternate variant of TBAB removing was offered by Doll [11]. The method consists of the extraction of TBAB by the volume of warm water tenfold to the reaction mass. After processing of the obtained water layer by ultrasound, TBAB passed to the suspension state, that allowed to isolate it with the help of a separation funnel. The described method allowed to single out about $96 \%$ of TBAB from the reaction mass.

The second way of TBAB removal from the desired product offered by Doll [11] is more simple in its performance, but it does not assume its repeated application. Hofmann elimination reaction lies in its basis: 

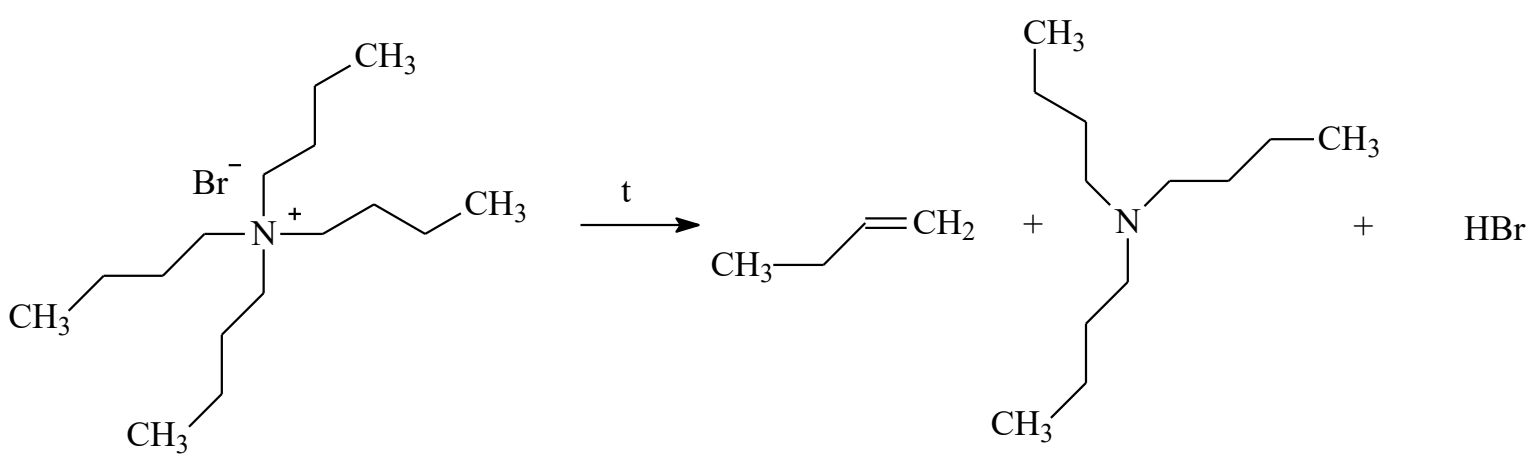

The offered scheme of TBAB decomposition reaction has been confirmed by IR-, NMR-spectroscopy and thermo-gravimetric analysis data.

The way consists in heating at $190{ }^{\circ} \mathrm{C} \mathrm{CCVO}$ with need conversion of EG in flow of nitrogen during 2.5 hours. Using the example of vernonia oil it has been shown $\left({ }^{1} \mathrm{~N}-\mathrm{NMR}\right)$ that the growth of unsaturation of epoxidized oil subjected to the carbonation, does not promote side reactions, both during the carbonation, and in the course of the catalyst decomposition [12]. Background of the research carbonization of epoxidized vegetable oils is the potential of multifunctional CC use as raw material for the synthesis of NIPU [5-7,13].

Also modification of epoxy composites by intercalation into the matrix of hydroxyurethane fragment is interesting [8]. Characteristics of NIPU based on cyclic carbonate from epoxidized oils obtained at equimolar ratios [Cyclic carbonate]:[Amin] presented in Table 5. In [15] has developed ways of using modified vegetable (cottonseed) oils as lubricants. Better strength properties provides linseed oil, due to its higher functionality (cyclic carbonate group content) (tab. 5). On the other hand $L i$ et al discovered that the full EG conversion of EVO not corresponding to the optimal properties of NIPU and they hazard a conjecture about negative influence steric factor (tab. 5). We can make a conclusion that most effective hardener of the reviewed for synthesis NIPU is ethylenediamine.

Table 5. Characteristics of NIPU based on cyclic carbonate from epoxidized oils.

\begin{tabular}{|c|c|c|c|c|c|c|}
\hline \multirow[b]{2}{*}{ Oil } & \multirow[b]{2}{*}{ Hardener } & \multicolumn{4}{|c|}{ Properties of NIPU } & \multirow[b]{2}{*}{ Reference } \\
\hline & & $\begin{array}{l}\text { Curing } \\
\text { conditions }\end{array}$ & ${ }^{*} \mathrm{~T}_{\mathrm{g}},{ }^{\circ} \mathrm{C}$ & $\begin{array}{l}\text { Elongation at } \\
\text { break, \% }\end{array}$ & $\begin{array}{c}\text { Tensile } \\
\text { strength, } \\
\text { MPa }\end{array}$ & \\
\hline \multirow{3}{*}{ ESBO } & Ethylenediamine (EDA) & \multirow{3}{*}{$\begin{array}{c}10 \text { hours at } 70 \\
{ }^{\circ} \mathrm{C} \text { and } 3 \text { hours } \\
\text { at } 100^{\circ} \mathrm{C}\end{array}$} & 34 & 140 & 0.82 & \multirow{3}{*}{6} \\
\hline & $\begin{array}{l}\text { Hexamethylenediamine } \\
\text { (HMDA) }\end{array}$ & & 18 & 170 & 0.33 & \\
\hline & $\operatorname{tris}(2$-aminoethyl)amine & & 43 & 70 & 1.50 & \\
\hline \multirow{3}{*}{ ESBO } & EDA & \multirow{3}{*}{$\begin{array}{c}10 \text { hours at } 70 \\
{ }^{\circ} \mathrm{C} \text { and } 3 \text { hours } \\
\text { at } 100{ }^{\circ} \mathrm{C}\end{array}$} & 38 & 90 & 5.77 & \multirow{3}{*}{7} \\
\hline & HMDA & & 35.3 & 190 & 3.80 & \\
\hline & Butylenediamine (BDA) & & 40 & 130 & 4.71 & \\
\hline ESBO & EDA & 10 hours at 70 & 20 & $240 \pm 30$ & $6 \pm 1$ & 13 \\
\hline
\end{tabular}




\begin{tabular}{|c|c|c|c|c|c|c|}
\hline & $\mathrm{BDA}$ & $\begin{array}{c}{ }^{\circ} \mathrm{C} \text { and } 3 \text { hours } \\
\text { at } 100{ }^{\circ} \mathrm{C} \text {. For } \\
\text { IPDA - } \\
\text { additionally } \\
12 \text { hours at } 70 \\
{ }^{\circ} \mathrm{C}\end{array}$ & 17 & $310 \pm 10$ & $2 \pm 0$ & \\
\hline & Isophoronediamine (IPDA) & \multirow{4}{*}{$\begin{array}{c}12 \text { hours at } 70 \\
{ }^{\circ} \mathrm{C}\end{array}$} & 40 & $200 \pm 30$ & $5 \pm 0$ & \\
\hline \multirow{3}{*}{ ELSO } & EDA & & 55 & $57 \pm 20$ & $18 \pm 2$ & \\
\hline & BDA & & 45 & $84 \pm 30$ & $17 \pm 2$ & \\
\hline & IPDA & & 60 & $1 \pm 0$ & $10 \pm 3$ & \\
\hline $\begin{array}{l}\text { ESBO with } \\
\text { the } \\
\text { conversion } \\
\text { of the epoxy } \\
\text { oxygen }(\%) \text { : }\end{array}$ & \multirow{5}{*}{ EDA } & \multirow{5}{*}{$\begin{array}{c}20-30 \text { hours at } \\
90-100{ }^{\circ} \mathrm{C}\end{array}$} & \multirow{5}{*}{$\mathrm{n} / \mathrm{a}$} & & & \multirow{5}{*}{10} \\
\hline 55.4 & & & & 232 & 2.63 & \\
\hline 74.3 & & & & 173 & 7.0 & \\
\hline 85.1 & & & & 163 & 6.9 & \\
\hline 90.9 & & & & 207 & 4.56 & \\
\hline
\end{tabular}

* Dynamic mechanical analysis data analysis

\section{CONCLUSIONS}

The analysis of literary data on the obtaining of cyclic carbonates on the basis of epoxidized vegetable oils has been carried out. The influence of the following factors on EVO carbonation reaction has thus been considered: the type of vegetable oil, the type and catalyst concentration, state of carbon dioxide, pressure and temperature. In all cases described in literature, the reaction of carbonation takes place at temperatures not lower than $100{ }^{\circ} \mathrm{C}$. The process is conducted both at the atmospheric, and at the increased (up to $6.0 \mathrm{MPa}$ ) pressure that in many respects determines its duration. It is possible to single out works where the synthesis of cyclic carbonates is carried out in the supercritical carbon dioxide environment (the pressure is over 7.38 MPa). Epoxidized soybean oil has mainly been used as the object of carbonation, but in some works epoxidized linseed, cotton seed and vernonia oils have been studied. The use of small water additions to intensify the carbonation process represents some interest. The issue of catalyst removing from the CCVO is also being discussed. Approaches to this process are ambiguous, besides, it is impossible to consider its necessity as proved.

The presence of side reactions in the path of EVO carbonation is stated in many works. The GPC data testify to it, in particular. However, there are practically no exact ideas about the ways of their account in literature. There is no consensus on the structure of received products, even in case that the method of CCVO synthesis described by different authors is similar. These are various data on molecular mass and viscosity of obtained cyclic carbonates at identical values of epoxy groups conversion. Also there is no consensus on the optimum of carbonation process temperature and pressure. It, naturally, affects the quality of results regard to the obtaining of NIPU on the basis of CCVO. Summarizing the aforesaid, it is possible to draw a conclusion about the insufficient study of carbonation process of epoxidized vegetable oils that are valuable renewable vegetable raw materials, and the necessity of further researches of this reaction for the purpose of obtaining NIPU with the required set of properties. 


\section{References}

[1] A. A. G. Shaikh, S. Sivaram, Chem. Rev. 96 (1996) 951-976.

[2] Rokicki G., Prog. Polym. Sci. 25 (2000) 259-342.

[3] O. Figovsky, L. Shapovalov, A. Leykin, O. Birukova, R. Potashnikova, International Letters of Chemistry, Physics and Astronomy 3 (2012) 52-66.

[4] M. North, R. Pasquale, C. Young, Green Chem. 12 (2000) 1514-1539.

[5] A.R. Mahendran, N. Aust, G. Wuzella, U. Müller, A. Kandelbauer, Journal of Polymers and the Environment 20(4) (2012) 926-931.

[6] B. Tamami, S. Sohn, G. L. Wilkes, Journal of Applied Polymer Science 92(2) (2004) 883-891.

[7] I. Javni, W. Zhang, Z. S. Petrovic, Journal of Applied Polymer Science 88 (2003) 29122916.

[8] P. G. Parzuchowski, M. Jurczyk-Kowalska, J. Ryszkowska, G. Rokicki, Journal of Applied Polymer Science 102(3) (2006) 2904-2914.

[9] P. Mazo, L. Rios, Journal of the American Oil Chemists' Society 90(5) (2013) 725-730.

[10] Z. Li, Y. Zhao, S. Yan, X. Wang, M. Kang, J. Wang, H. Xiang, Catal. Lett. 123 (2008) 246-251.

[11] K. M. Doll, S. Z. Erhan, Green Chem. 7 (2005) 849-854.

[12] N. Mann, S. K. Mendon, J. W. Rawlins, S. F. Thames, Journal of the American Oil Chemists' Society 85(8) (2008) 791-796.

[13] M. Bähr, R. Mülhaupt, Green Chem. 14 (2012) 483-489.

[14] S.-C. Chua, X. Xu, Z. Guo, Process Biochemistry 47(10) (2012) 1439-1451.

[15] L. Zhang, Y. Luo, Z. Hou, Z. He, W. Eli, Journal of the American Oil Chemists' Society 91(1) (2014) $143-150$.

[16] K. Motokura, S. Itagaki, Y. Iwasawa, A. Miyaji, T. Baba, Green Chem. 11 (2009) 18761880.

[17] B. K. Sharma, A. Adhvaryu, Z. Liu, S. Z. Erhan, Journal of the American Oil Chemists' Society 83(2) (2006) 129-136.

[18] J. Sun, J. Ren, S. Zhang, W. Cheng, Tetrahedron Lett. 50 (2009) 423-426. 